\title{
GEOCHEMISTRY OF TERTIARY SEQUENCE IN SHAHBAJPUR-1 WELL, HATIA TROUGH, BENGAL BASIN, BANGLADESH: PROVENANCE, SOURCE WEATHERING AND PROVINCE AFFINITY
}

\author{
Dhiman Kumer Roy* and B.P. Roser \\ Dept. of Geoscience, Shimane University, 1060 Nishikawatsu, Matsue, Shimane 690-8504, Japan \\ *Corresponding author (e-mail: dhimans14@yahoo.com)
}

\begin{abstract}
Major and trace element compositions of Neogene sandstones and mudrocks from the Shahbajpur-1 (SB-1) well, Hatia trough, Bengal basin, Bangladesh were determined to examine their geochemical characteristics and provenance, in relation to Himalayan uplift, sediment dispersal, and correlation of coeval successions in a basinal context. Major and trace element abundances in the SB-1 succession vary vertically, with $\mathrm{SiO}_{2}$ content decreasing and $\mathrm{Al}_{2} \mathrm{O}_{3}$ increasing from the older (Surma and Tipam Groups) to younger (Dupi Tila Group) sediments. Marked geochemical fractionation between sandstones and mudrocks reflects advanced hydrodynamic sorting, and relative enrichment of several elements (e.g., $\mathrm{TiO}_{2}, \mathrm{Zr}$, Ce, $\mathrm{Th}, \mathrm{Cr}$ ) suggests sporadic heavy mineral concentration in some sandstones. Major and trace element provenance discriminants indicate a uniform felsic source (Himalayan detritus and recycled sediments) for the entire succession. Values for the Chemical Index of Alteration (CIA) record moderate weathering in the source, and non-steady state conditions produced by Himalayan uplift. Comparison between the Hatia trough samples and coeval Sylhet trough (P2) sediments shows that the more distal SB-1 succession is compositionally more uniform. Strong similarity in geochemical composition between SB-1 and P2 support the hypothesis that the Hatia trough is an extension of P2, fed by the same dispersal system.
\end{abstract}

Key words: Geochemistry, provenance, weathering, sorting, Bengal basin, Bangladesh.

সারাংশ: এই গবেষণায় শাহবাজপুর-১ (SB-১), হাতিয়া ট্রাফ, বঙ্গীয় বেসিন, বাংলাদেশ এর নিওজিন বেলেপাথর ও কর্দম শিলার প্রধান ও স্বল্প পরিমানের ট্রেস উপাদানের ভূরাসায়নিক বৈশিষ্ট্য এবং তাদের উৎস সম্পর্কে ধারণা প্রদান করা হয় এবং এর সঙ্গে হিমালয়ের বর্ধনশীলতা, পললের বিন্যাস এবং বেসিনের সমসাময়িক শিলাস্তরের সম্পর্ক নির্ণয় করা হয়েছে। SB-১ শিলাস্তরের প্রধান ও স্বল্প পরিমানের উপাদান এর পর্যাপ্ততা উল্লম্বিকভাবে ভিন্নতার সাথে $\mathrm{SiO}_{2}$ এর পরিমাণ হ্রাস এবং $\mathrm{Al}_{2} \mathrm{O}_{3}$ বৃদ্ধির প্রবণতা প্রাচীনতম শিলাস্তর (সুরমা এবং টিপাম শ্রেণী) থেকে নবীনতম শিলাস্তরে (ডুপি টিলা শ্রেণী) দেখা যায়। বেলেপাথর ও কর্দম শিলার ভূ-রাসায়নিক বিন্যস্ততায় প্রতিফলিত হয় যে, উন্নততর হাইড্রোডাইনামিক শ্রেণী বিন্যস্ততা এবং বিভিন্ন উপাদানের $\left(\mathrm{TiO}_{2}, \mathrm{Zr}, \mathrm{Ce}, \mathrm{Th}, \mathrm{Cr}\right)$ বৃদ্ধির প্রবণতা যা দেখায় যে, বেলেপাথরের মধ্যে বিক্ষিপ্তভাবে ভারী মাণিকের অধিক্য। মেজর এবং ট্রেস উপাদান দেখায় যে, সমস্ত শিলাস্তরের উৎস ফেলসিক (হিমালয়ের শিলা এবং পূর্ণআবর্তন পলল)। কেমিক্যাল অলটারেশনের ইনডেক্স (CIA)এর পরিমাণ প্রমাণ করে মধ্যম আবহবিকার গ্রস্থতা এবং অসম সুস্থিত অবস্থা যাহা হিমালয়ের উর্দ্ধ বর্ধনশীলতার দ্বারা পরিচালিত। তুলনামূলকভাবে হাতিয়া ট্রাফের পলল সিলেট ট্রাফ $\left(\mathrm{P}_{2}\right)$ এর পললের থেকে গঠনগতভাবে অধিক সমসত্ব। SB-১ এবং $\mathrm{P}_{2}$ এর ভূ-রাসায়নিক গঠন প্রমাণ করে যে, হাতিয়া ট্রাফ $\mathrm{P}_{2}$ এর বর্ধিত অংশ যা একই ধরনের পলনের বিন্যাস দ্বারা গঠিত।

\section{Introduction}

The Hatia trough is located in the southern part of the Bengal basin, near the Bay of Bengal (Fig. 1). The Bengal basin has attracted considerable interest recently, because its sediment fill provides a record of Himalayan exhumation and tectonism (Alam et al. 2003; Rahman and Faupl 2003; Rahman and Suzuki 2007a, b: Najman et al. 2008; Hossain et al. 2010). The Bengal basin in Bangladesh has traditionally been divided into three major geological provinces (Fig. 1), here denoted P1 (NW shelf), P2 (Sylhet trough) and P3 (Chittagong Tripura Folded Belt, or CTFB) (Reimann 1993; Najman, 2006). These authors noted that the three geological provinces may have had differing geological histories. Consequently, each province must be characterized individually, before the relationship between them and their evolution with time can be fully understood.

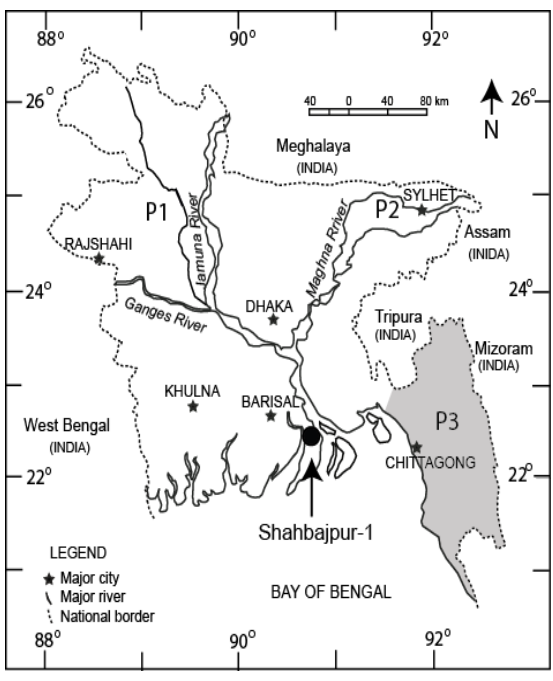

Figure 1 Map showing the location of the Shahbajpur-1 drill hole in the Hatia trough, Bengal basin, Bangladesh. P1, P2, P3Geological provinces (see text) (after Reimann 1993; Uddin and Lundberg 1999; Alam et al. 2003). 
Najman et al. (2008) proposed that the Bengal basin began to receive Himalayan sediments during the Oligocene, at $\sim 38 \mathrm{Ma}$. The Bengal basin is thus an ideal location to examine the tectonic uplift and erosion history of the Himalaya, and also paleo-weathering. It is well established that Himalayan uplift was the dominant driver for Miocene global climatic fluctuation (Raymo and Ruddiman 1992). The Himalayan-derived sediments of the Bengal basin are thus archives of the changing patterns of climate and sediment dispersal systems.

The mineralogical and geochemical compositions of sediments are influenced by numerous factors, including source rock composition, source weathering, sorting, heavy mineral concentration, tectonic setting of the depositional basin, and post-depositional effects such as diagenesis (Johnsson 1993, Roser 2000). Critical evaluation of the geochemical composition of sediments can determine the significance of these factors in individual sedimentary successions, as shown by many recent papers in the literature (Campos and Roser 2007; Hossain et al. 2010; Dinis et al. 2011; Long et al. 2011; Yang et al. 2011). Compositional variations of sediments are a valuable tool in the reconstruction of paleoenvironments and climate change (Clift et al. 2008; Yang et al. 2008).

Our present study deals with the geochemical composition of Tertiary sediments from the Shahbajpur-1 (SB-1) drill hole in the Hatia trough. Rahman and Faupl (2003) and Rahman and Suzuki (2007a, b) carried out geochemical investigations of Neogene P2 Surma Group mudstones and sandstones, respectively. Hossain et al. (2010) investigated the geochemical composition of Paleogene and Neogene sediments in the same province, to examine variations in provenance and source weathering over a large time span. Most geochemical studies in Bangladesh have been directed at Provinces 2 .

The Hatia trough is an extension of the Province 2 Sylhet basin, located to the northeast Bengal basin. Alam et al. (2003) suggested that the stratigraphy and sedimentation pattern of the Hatia trough should be considered separately, and indicated that it received sediments from all three provinces. Najman et al. (2008) suggested that the southern part of the Bengal basin could be correlated with P2, based on provenance study of Paleogene sediments from P1 and P2. Consequently, it is crucial to determine the composition of sediments in the Hatia trough, and evaluate if they are geochemically correlative with P2.
In this study we examine the geochemical fingerprints in a suite of Tertiary sandstones and mudstones from the Shahbajpur-1 drill hole to test possible correlation with P2, in terms of source rock composition, weathering conditions, effects of sedimentary processes, depositional setting, and post-depositional effects. This study will help in understanding the geochemical evolution of the Hatia trough sediments, and the control of provenance, weathering and sediment routing in the Bengal foredeep, and thus contribute to basin-wide regional correlation.

\section{Geological background}

The Bengal basin formed in response to the continentcontinent collision of India and Eurasia that built the Himalaya, which then delivered sediments to the adjacent foreland basin in the south. The Bengal basin is located at the junction of the Indian, Eurasian and Burmese plates, and is bounded by the Indian shield in the west, by the Himalaya in the north, and the IndoBurman ranges in the east. It contains one of the thickest sedimentary piles in the world (Alam et al. 2003).

Drill hole SB-1 is located in the southern part of the central deep basin in the Hatia trough. The Hatia trough is bounded by the Chandpur Barishal high in the northwest, and by the Chittagong-Tripura Fold Belt in the southeast. Structurally the Hatia trough is characterized by NNW-SSE trending anticline structure in which the eastern flank dips relatively gently, and deformation is less than in the western flank (BAPEX 1995; Mondal et al. 2009; Rahman et al. 2011).

A detailed account of the stratigraphy in SB-1 has been given by BAPEX (1995). The stratigraphic succession and sample positions are summarized in Table 1. The succession ranges from Miocene to Recent in age, although the base is not seen. The SB-1 succession is divided into four sequences named SBsequence 1, -2, -3 and -4 (BAPEX 1995, Mondal et al. 2009). Three of these sequences have been assigned to the traditional stratigraphic succession of Bangladesh, i.e. the Surma Group (SB-sequence 3 and 4) and the Tipam Group (SB-sequence 2) (BAPEX 1995; Rahman et al. 2011). However, SB-sequence 1 has not yet been assigned to any group. We here tentatively assign SB-sequence 1 to the Dupi Tila Group, because in traditional Bangladesh stratigraphy the Dupi Tila Group overlies the Tipam Group. 
Table 1 Stratigraphy, lithology and sample depths in the Shahbajpur-1 drill hole, Hatia trough (after BAPEX 1995; Mondal et al. 2009; Rahman et al. 2011). Sam. - Sample depth.

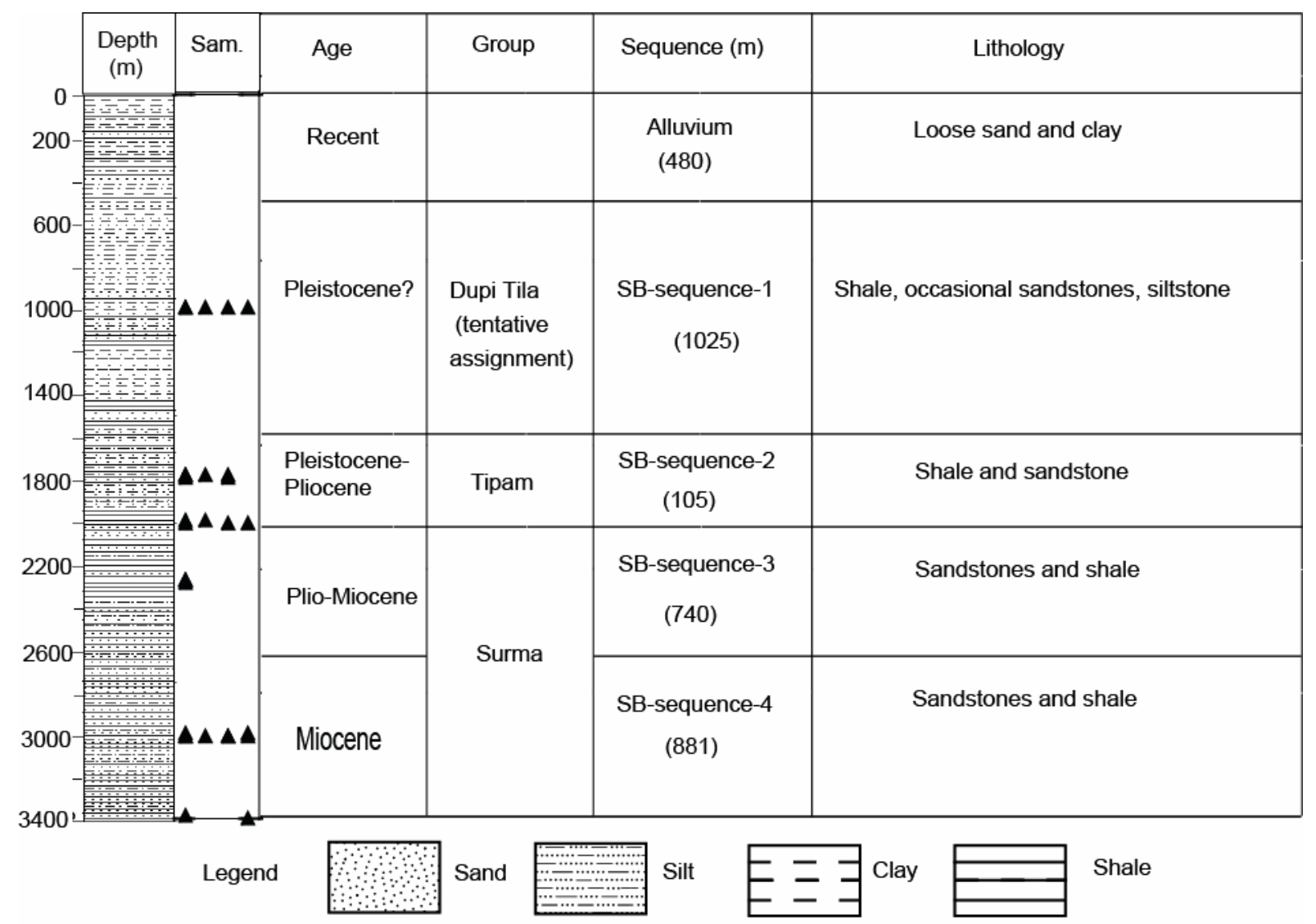

The lowermost Surma Group (SB-sequence 3 and 4) consists of fine-grained, well-indurated, thickly-bedded sandstones, siltstones and shales(BAPEX1995; Rahman et al. 2011) in its lower part. These sediments were deposited in an estuarine to marshy environment (Mondal et al. 2009). The upper part consists of fine-to medium-grained sandstones, siltstones and shales (BAPEX 1995; Rahman et al. 2011) that were deposited in a shallow marine to tidal environment (Mondal et al. 2009). The Tipam Group (SB-sequence 2) is composed of shale with occasional sandstone beds. These were deposited in a prograding deltaic environment (BAPEX 1995; Mondal et al. 2009). Dupi Tila Group (SBsequence 1) consists of shales with occasional sandstones and calcareous siltstones, deposited in deltaic to marine environments (BAPEX 1995; Mondal et al. 2009).

\section{Material and Methods}

Sample suite

Samples of both sandstones and mudrocks (siltstones and mudstones) were collected from the SB-1 deep drill hole $(\sim 3400 \mathrm{~m})$. Thirty fresh core samples from the Surma ( $\mathrm{n}=19 ; 8$ sandstones, 11 mudrocks), Tipam ( $\mathrm{n}=$ 6; 3 sandstones, 3 mudrocks) and Dupi Tila $(n=5$, all mudrocks) Groups were selected for whole-rock geochemical analysis. The number of samples collected for each group was controlled by suitability and availability from drill core. Sample positions are listed in Tables 1 and 2.

\section{Analytical methods}

The drill core samples were chipped to $<1 \mathrm{~cm}$ using a manual splitter. The chipped samples were then washed in distilled water to remove any dust, and dried at $110^{\circ} \mathrm{C}$. The chips were subsequently crushed in a tungsten carbide ring mill, with mill times generally of 30-45 seconds, following the methodology of Roser et al. (1998). Total loss on ignition (LOI) was then determined gravimetrically, by ignition of 8-10 g subsamples for at least $2 \mathrm{~h}$ at $1020^{\circ} \mathrm{C}$. These ignited subsamples were used for the whole-rock analysis.

Whole-rock geochemical compositions were determined by X-Ray fluorescence analysis at Shimane University, 
using a Rigaku RIX 2000 spectrometer equipped with an Rh-anode X-ray tube. Major element and 14 trace element (Ba, Ce, Cr, Ga, Nb, Ni, Pb, Rb, Sc, Sr, Th, V, $\mathrm{Y}, \mathrm{Zr}$ ) abundances were determined from glass fusion beads prepared with an alkali flux (80\% lithium tetraborate $\left(\mathrm{Li}_{2} \mathrm{~B}_{4} \mathrm{O}_{7}\right)$ and $20 \%$ lithium metaborate $\left(\mathrm{LiBO}_{2}\right)$ ), in a flux to sample ratio of 2:1 (Kimura and Yamada 1996). Calibration and correction for spectral interferences followed the methodology of Kimura and Yamada (1996).

\section{Results}

Major and trace elements compositions of the sandstones and mudrocks by group and lithotype are presented in Table 2, on an anhydrous normalized basis, as used for all plotting and comparisons. The trace element data were also normalized, using the same normalization factors. Original analytical total (anhydrous) and hydrous LOI data are also given in Table 2, to permit recalculation to a hydrous basis if desired.

\section{Chemical composition}

Surma Group sandstones contain 76.16 wt\% (range 72.17-79.05 wt \%) $\mathrm{SiO}_{2}$ on average, compared to 74.91 wt\% (71.97-76.45 wt \%) in the Tipam Group. Average $\mathrm{SiO}_{2}$ contents of Surma and Tipam mudrocks are also

very similar (68.73 and 69.62 wt\%, respectively), falling slightly in the Dupi Tila Group (66.42 wt\%). Surma Group mudrocks average $15.0 \quad w t \% \quad \mathrm{Al}_{2} \mathrm{O}_{3}$ (12.87-16.49 wt \%). Tipam mudrocks have a similar $\mathrm{Al}_{2} \mathrm{O}_{3}$ average of $14.54 \mathrm{wt} \%$ (12.87-15.45 wt\%), but contents increase to an average of $17.32 \mathrm{wt} \%$ (16.5817.76 wt\%) in the Dupi Tila mudrocks. Average $\mathrm{K}_{2} \mathrm{O}$ contents of Surma and Tipam Groups mudrocks are almost identical (3.09 wt\% and 3.02 wt\% respectively), whereas that in the younger Dupi Tila Group mudrocks is slightly greater (3.51 wt\%). Average $\mathrm{Na}_{2} \mathrm{O}$ content gradually decreases from the Surma (1.36 wt\%) through Tipam (1.30 wt\%) and Dupi Tila (1.25 wt\%) mudrocks.

Almost all trace elements are more abundant in Surma and Tipam mudrocks than in their companion sandstones, except for $\mathrm{Zr}$ (enrichment factor 0.89) in the Surma Group, and Ce (EF 0.92), Y (EF 0.98) and Zr (EF 0.78) in the Tipam Group mudrocks are similar, whereas those in the Dupi Tila Group are slightly depleted in $\mathrm{Zr}$ and enriched in $\mathrm{Cr}, \mathrm{Ga}, \mathrm{Rb}$ and $\mathrm{V}$, on average (Table 2).

\section{Chemical classification}

Several geochemical classification schemes have been used in the literature to measure mineralogical maturity, quartz and clay ratios, and dominance of lithic fragments and feldspar (Pettijohn et al.1972; Herron 1988). Using the classification scheme of Herron (1988), almost all Surma and Tipam samples fall in the wacke and litharenite fields (Fig. 2). Some Surma mudrocks and all Dupi Tila mudrocks are classified as shales, consistent with their appearance. This suggests Surma and Tipam sediments are more mature and contain more quartz than Dupi Tila equivalents.

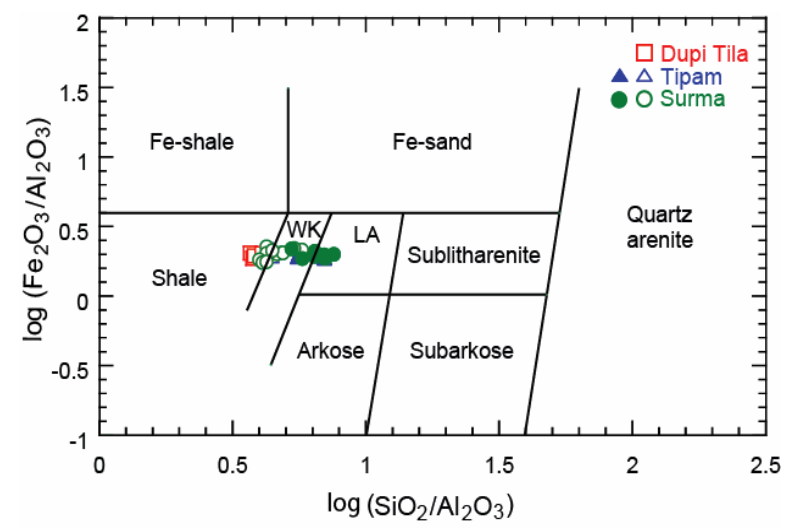

Figure $2 \mathrm{Log}\left(\mathrm{SiO}_{2} / \mathrm{Al}_{2} \mathrm{O}_{3}\right)$ vs. $\log \left(\mathrm{Fe}_{2} \mathrm{O}_{3} / \mathrm{K}_{2} \mathrm{O}\right)$ diagram (Herron 1988) for the Shahbajpur-1 drill hole sandstones and mudrocks. WK - wacke; LA - litharenite.

In the Pettijohn et al. (1972) diagram almost all the sediments cluster in the litharenite field, although some Surma and Tipam sandstones are classified as arkoses (Fig. 3). The distribution of the sediments on this plot also suggests that the Dupi Tila sediments are less mature than Surma and Tipam equivalents, consistent with the Herron diagram (Fig. 2). Overall, these classifications indicate that the sediments are characterized by intermediate maturity.

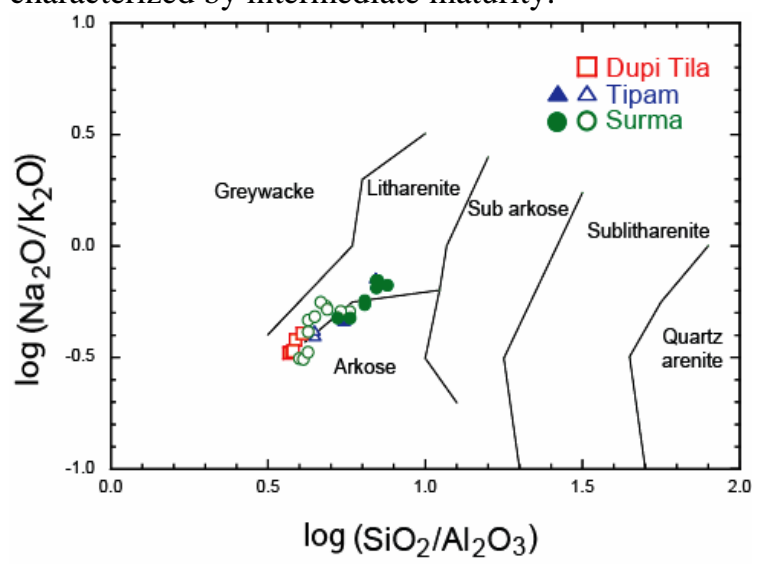

Figure $3 \mathrm{Log}\left(\mathrm{SiO}_{2} / \mathrm{Al}_{2} \mathrm{O}_{3}\right)$ vs. $\log \left(\mathrm{Na}_{2} \mathrm{O} / \mathrm{K}_{2} \mathrm{O}\right)$ diagram (after Pettijohn et al. 1972) for the Shahbajpur-1 drill hole sandstones andmudrocks. 
Table 2. Whole rock major (wt \%) and trace element (ppm) analyses of sandstones and mudrocks from the Shahbajpur-1 drill hole, Bangladesh.

Index: SaNR - sample number; Lith - lithology; total iron as $\mathrm{Fe}_{2} \mathrm{O}_{3}$; LOI- Loss on ignition. Note that data are tabulated on an anhydrous normalized basis. The normalizing factors were applied to both the major and trace element data. Original anhydrous analysis total (Total*) and LOI data are included to allow recalculation to a hydrous basis if desired.

\begin{tabular}{|c|c|c|c|c|c|c|c|c|c|c|c|c|c|c|c|c|c|c|c|c|c|c|c|c|c|c|c|c|}
\hline SaNr & epth (m) & Lith & $\mathrm{SiO}_{2}$ & $\mathrm{TiO}_{2}$ & A & ${ }_{2} \mathrm{O}_{3}$ & $\mathrm{MnO}$ & $\mathrm{MgO}$ & $\mathrm{CaO}$ & $\mathrm{Na}_{2} \mathrm{O}$ & $\mathrm{K}_{2} \mathrm{O}$ & $\mathrm{P}_{2} \mathrm{O}_{5}$ & $\mathrm{Ba}$ & $\mathrm{Ce}$ & $\mathrm{Cr}$ & $\mathrm{Ga}$ & $\mathrm{Nb}$ & $\mathrm{Ni}$ & $\mathrm{Pb}$ & $\mathrm{Rb}$ & $\mathrm{Sc}$ & $\mathrm{Sr}$ & Th & $\mathrm{v}$ & $Y$ & $\mathrm{Zr}$ & LOI & Total $^{*}$ \\
\hline \multicolumn{29}{|c|}{ Dupi Tila Group } \\
\hline RR 64 & 999 & mst & 66.58 & 0.84 & 17.19 & 6.85 & 0.11 & 2.57 & 0.97 & 1.30 & 3.44 & 0.14 & 517 & 84 & 111 & 22 & 18 & 61 & 30 & 185 & 17 & 138 & 20 & 129 & 33 & 203 & 5.37 & 99.20 \\
\hline R 65 & & mst & 65.40 & 0.83 & 17.76 & 7.34 & 0.11 & 2.66 & 0.95 & 1.19 & 3.60 & 14 & 532 & 78 & 116 & 21 & 17 & 62 & 31 & 192 & 18 & 141 & 21 & 135 & 34 & 195 & 5.36 & 98.82 \\
\hline 66 & 02 & $z$ & 66.30 & 0.84 & 17.65 & 6.72 & 0.10 & 2.53 & 91 & 1.21 & 3.60 & 13 & 531 & 85 & 13 & 21 & 18 & 61 & 4 & 190 & 16 & 40 & ( & 134 & 33 & 79 & 93 & 99.01 \\
\hline 67 & 04 & & 66.33 & 0.87 & 17.43 & 6.90 & 0.10 & .54 & 0.95 & 1.20 & 3.55 & & 541 & 90 & 12 & 21 & 10 & 65 & 34 & 189 & 17 & 20 & 1 & 138 & 35 & & 22 & 98.57 \\
\hline $\mathrm{R} 68$ & 006 & zst & 67.47 & 0.78 & 16.58 & 6.78 & 0.10 & 45 & 0.98 & 1.36 & 3.35 & 0.15 & 499 & 81 & I0 & 20 & 16 & 58 & 30 & 180 & 15 & 144 & 19 & 126 & . & [ & 11 & 98.62 \\
\hline \multicolumn{3}{|c|}{ Average mudrock } & 66.42 & 0.83 & 17.32 & 6.92 & 0.11 & 2.55 & 0.95 & 1.25 & 3.51 & 0.14 & 524 & 83 & 112 & 21 & 18 & 62 & 32 & 187 & 16 & 140 & 20 & 132 & 33 & 196 & 5.20 & 98.84 \\
\hline \multicolumn{29}{|c|}{ Tipam Group } \\
\hline$R 69$ & 1795 & f sst & 71.97 & 0.72 & 13.03 & 5.34 & 0.07 & 2.29 & 2.37 & 1.29 & 2.80 & 0.12 & 488 & 74 & 74 & 16 & 16 & 40 & 2 & 151 & 11 & 135 & 7 & 93 & 29 & 47 & 4.32 & 98.61 \\
\hline 70 & 96 & mst & 68.99 & 0.83 & 15.45 & 6.62 & 0.05 & 2.62 & 1.03 & 1.21 & 3.07 & 0.13 & 482 & 79 & 110 & 19 & 17 & 71 & 28 & 161 & 15 & 136 & 17 & 123 & 30 & 23 & 4.18 & 99.10 \\
\hline 71 & ( & m sst & .45 & 0.70 & & 4.09 & 0.06 & 171 & 2.31 & & & & & 100 & 64 & 10 & & & 6 & & 8 & & & & & & & 98.74 \\
\hline 72 & 98 & $\mathrm{~m}$ sst & 76.32 & 0.68 & 10.95 & 4.14 & 0.06 & 1.71 & 22 & 1.58 & 2.20 & & 397 & 89 & 59 & 14 & 14 & 2 & 9 & 116 & 9 & 43 & 6 & 79 & 2 & & 25 & 8.98 \\
\hline R 73 & 1800 & zst & 68.05 & 0.81 & 15.31 & 6.30 & 0.08 & 69 & 2.04 & 1.35 & 3.24 & 12 & 526 & 88 & 91 & 19 & 17 & 47 & 24 & 170 & 15 & 148 & 21 & 111 & 33 & 62 & 23 & 98.46 \\
\hline DR 74 & 1802 & zst & 71.82 & 0.73 & 12.87 & 5.58 & 0.07 & 2.39 & 32 & 1.34 & 2.77 & 12 & 469 & 75 & 77 & 15 & 16 & 40 & 25 & 150 & 13 & 137 & 17 & 95 & 29 & 210 & 4.45 & 98.44 \\
\hline \multirow{2}{*}{\multicolumn{3}{|c|}{$\begin{array}{l}\text { Average sst } \\
\text { Average mudrock }\end{array}$}} & 74.91 & 70 & 11.62 & 4.52 & 0.06 & 91 & 2.30 & 1. & 2.39 & 0.13 & 426 & 88 & 66 & 14 & 15 & 32 & 19 & 27 & 9 & 11 & 18 & 82 & 31 & 327 & 63 & 78 \\
\hline & & & 69.62 & 79 & 14.54 & 6.17 & 06 & 57 & 1.80 & 1.30 & 02 & 0.13 & 492 & 81 & 93 & 17 & 17 & 53 & 26 & 160 & 15 & 140 & 18 & 110 & 31 & 23 & 62 & 8.67 \\
\hline$E F(m u$ & drock/sands & & 0.93 & 1.13 & 1.25 & 1.36 & 1.02 & 1.35 & 0.78 & 0.90 & 1.26 & 0.94 & 1.15 & 0.92 & 1.40 & 1.27 & 1.15 & 1.63 & 1.35 & 1.26 & 1.55 & 1.00 & 1.04 & 1.34 & 0.98 & 0.7 & 1.27 & \\
\hline \multicolumn{29}{|c|}{ 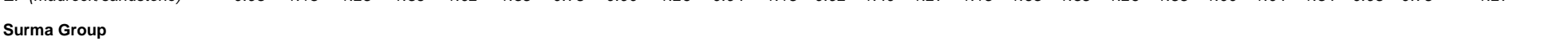 } \\
\hline DR 75 & 2012 & zs & 67 & 0.83 & 1 & 5.90 & 0.06 & 49 & 2.08 & 1.55 & 2.89 & & 486 & 8 & 93 & 18 & 1 & 48 & 21 & 16 & 13 & 143 & 19 & 104 & 33 & 256 & 9 & 98.64 \\
\hline & & & & & & & & & & & & & & & & & & & & & & & & & & & & 98.96 \\
\hline 77 & 14 & zs & 39 & 0.87 & 15.86 & 6. & 0 & 2.64 & 1.93 & 1.48 & 8 & & 509 & 87 & 95 & 19 & ( & & 9 & 160 & I & & 21 & 13 & ( & & 2 & 98.66 \\
\hline 78 & 15 . & $z$ & 01 & 0.83 & & 5. & & & 2.09 & 148 & & & 471 & 95 & 98 & 1 & 1 & & & & & & 1 & & & & & 98.94 \\
\hline & & & & 0.84 & & & & & & & & & & 9 & 101 & & & & & & & & & & & & & 3.82 \\
\hline : & & $\mathrm{zs}$ & & & & & & & & & & & & & & & & & & & & & & & & & & 8.67 \\
\hline L & 2293 & $2 s$ & c & 5 & & 6.2 & 0 & & & 1. & & & 56 & 8 & & & & & & & & & 4 & 11 & & & & 18 \\
\hline & & & & & & & & & & & & & & & & & & & & & & & & - & & & & 99 \\
\hline & & & & 0.82 & & & & & & & & & & & & & & & & & 10 & & & 16 & & & & 48 \\
\hline & & $f$ & & & & & & & & & & & & 9 & 102 & & & & & & 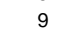 & & & 9 & & & & 8.78 \\
\hline & & & & & & & & & & & & & & 7 & 86 & & & & & & 8 & & & 6 & & & & 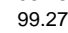 \\
\hline & 30 & ZS & & 0.87 & & & & & & & & & 4 & 8 & 109 & 2 & & & 25 & 16 & t & & 9 & 7 & & & 4 & 38 \\
\hline & 301 & m sst & & & & 4. & & & & & & & & & & & & & & & & & & & & & & \\
\hline & 301 & zs & & & & & & & & & & & & & & & & & & & & & & & & & & 32 \\
\hline & 301 & & & 0.70 & & & & & & & & & & 8 & 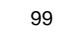 & & & & & & & & & & 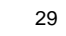 & & & \\
\hline & 3021 & $\mathrm{fss}$ & 72.17 & 0.75 & & 5.92 & 0.05 & & & & 2. & & 4 & 8 & 105 & 15 & & & 4 & & r & & & & & & & \\
\hline & 302 & $\mathrm{~m}$ & 72.3 & 0.75 & & & & & & & & & & & & & & & & & & & & & & & & \\
\hline & 340 & $f s$ & & & & & & & & & & & & & & & & & & & 9 & & & & & & & \\
\hline DR 93 & 3408 & f sst & 77.57 & 0.57 & 10.96 & 4.21 & 0.04 & 1.67 & 1.03 & 1.57 & 2.25 & 0.11 & 422 & 68 & 57 & 10 & 13 & 32 & 18 & 113 & 8 & 120 & 17 & 65 & 22 & 258 & 2.62 & 98.78 \\
\hline \multirow{2}{*}{\multicolumn{3}{|c|}{$\begin{array}{l}\text { Average sst } \\
\text { Average mudrock }\end{array}$}} & & & & & & & & & & & & 78 & 80 & 1 & & & 22 & & 10 & & 18 & 77 & 26 & & & \\
\hline & & & & & & & & & & & & & & & 96 & 17 & & & 27 & & 14 & & 20 & & & & & \\
\hline \multicolumn{3}{|c|}{ F(mudrocks } & 0.90 & 1.26 & 1.28 & 1.33 & 1.37 & 1.41 & 1.86 & 0.98 & 1.31 & 1.23 & 1.18 & 1.10 & 1.20 & 1.40 & 1.24 & 1.29 & 1.23 & 1.32 & 1.45 & 1.05 & 1.14 & 1.48 & 1.26 & 0.89 & 1.63 & \\
\hline
\end{tabular}

Lithology codes: $\mathrm{m}$ sst - medium sandstone; $\mathrm{fsst}$ - fine and very fine grained sandstone; zst -siltstone; $\mathrm{mst}$ - mudstone. 


\section{Mineralogical controls on whole-rock geochemistry}

Bivariate plots of major element abundances versus $\mathrm{Al}_{2} \mathrm{O}_{3}$ have been used to investigate the relationship between elements, and the control of sorting and specific minerals on sediment composition (Fig. 4).

The marked negative linear trend for $\mathrm{Al}_{2} \mathrm{O}_{3}-\mathrm{SiO}_{2}$ (Fig. $4 \mathrm{a}$ ) indicates that the major element composition of these sediments is mainly controlled by the relative proportion of quartz and feldspar versus clay minerals. Strong positive linear correlation between $\mathrm{Al}_{2} \mathrm{O}_{3}$ and $\mathrm{K}_{2} \mathrm{O}$ (Fig. 4b) suggests illitic clays are the main host for potassium. No correlation exists between $\mathrm{Al}_{2} \mathrm{O}_{3}$ and $\mathrm{CaO}$ (Fig. 4c), suggesting multiple controls, such as varying proportions of calcic plagioclase, and the presence of small amounts
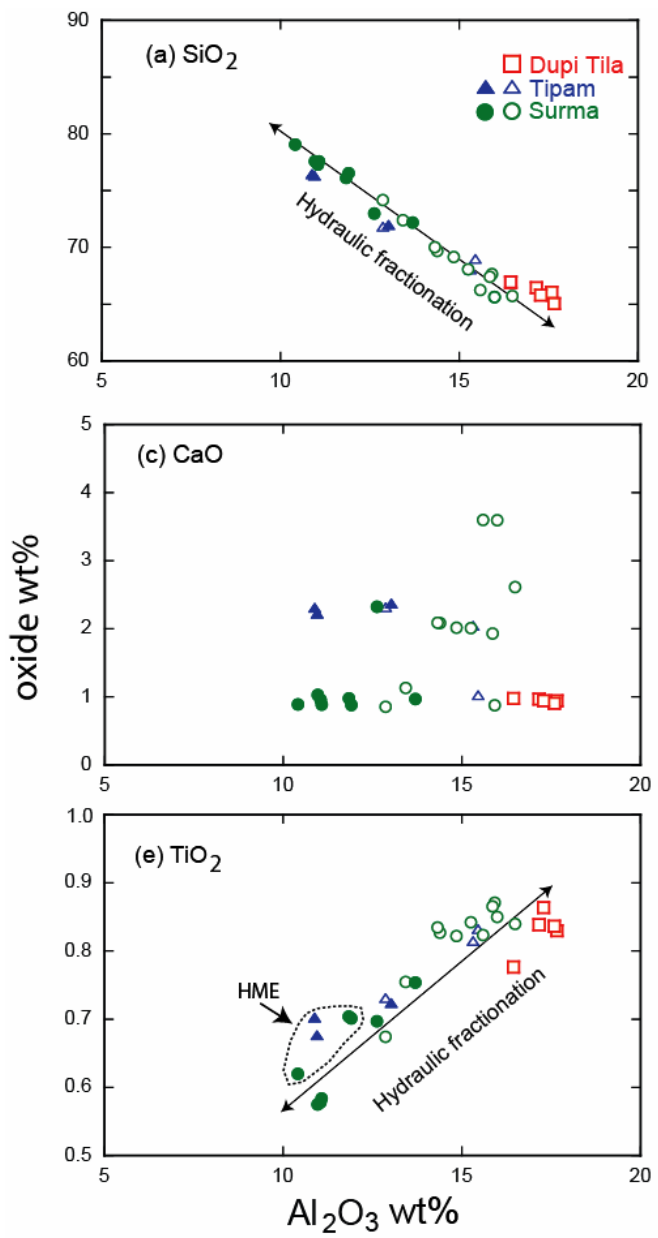

of carbonate cement in some samples. Weak negative correlation between $\mathrm{Al}_{2} \mathrm{O}_{3}$ and $\mathrm{Na}_{2} \mathrm{O}$ (Fig. 4d) suggests higher contents of sodic plagioclase in the sandstones relative to most of the mudrocks. Positive correlation between $\mathrm{TiO}_{2}, \mathrm{MgO}$ (Fig. 4e and f) and $\mathrm{Fe}_{2} \mathrm{O}_{3}$ (not illustrated) with $\mathrm{Al}_{2} \mathrm{O}_{3}$ is compatible with their residence in clay minerals produced from weathering of ferromagnesian minerals. Higher $\mathrm{TiO}_{2}$ and MgO contents at $>15$ wt $\% \mathrm{Al}_{2} \mathrm{O}_{3}$ implies that the Surma and Tipam mudrocks contain a greater mafic component than Dupi Tila equivalents. Positive correlation between $\mathrm{Al}_{2} \mathrm{O}_{3}$ and $\mathrm{P}_{2} \mathrm{O}_{5}$ (not illustrated) suggests association of phosphorus with clays rather than apatite.
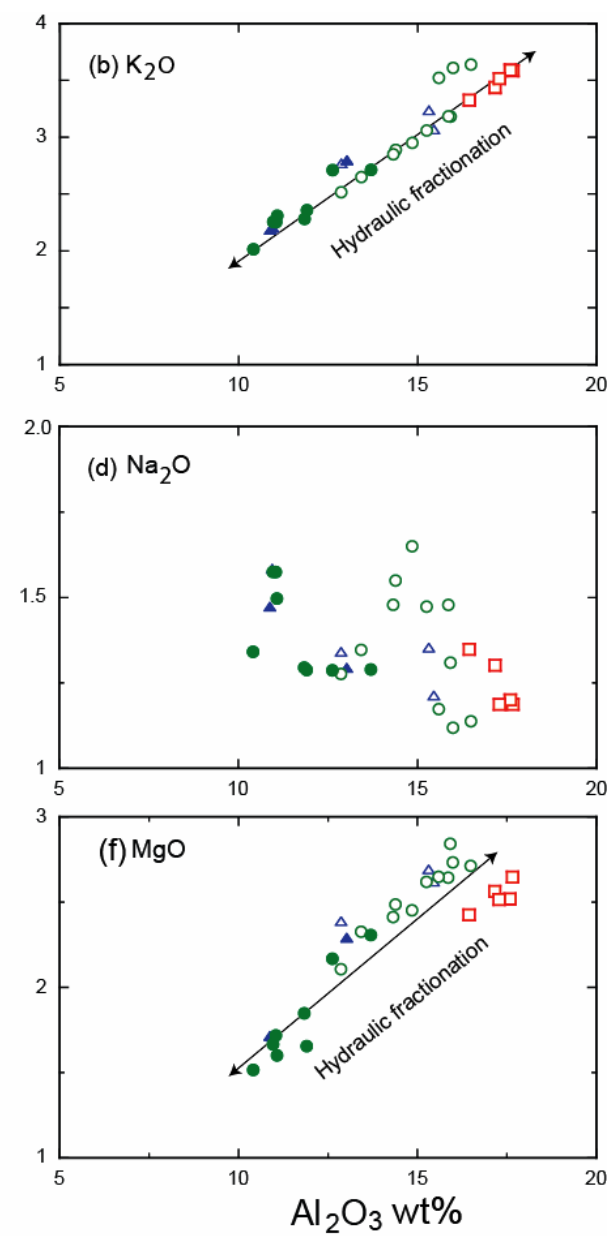

Figure 4 Selected major element- $\mathrm{Al}_{2} \mathrm{O}_{3}$ variation diagrams for the Shahbajpur-1 drill hole sandstones and mudrocks. Data for this and the following figures are plotted on an anhydrous normalized basis. HME- heavy mineral effects.

Similar trends are evident among the trace elements. Strong positive correlation of mobile elements such as $\mathrm{Ba}$ and $\mathrm{Rb}$ with $\mathrm{Al}_{2} \mathrm{O}_{3}$ (Fig. 5a and b) suggests their association with clay minerals, and marked hydrodynamic separation of quartz and clays. Positive correlation between the immobile element $\mathrm{Th}$ and $\mathrm{Al}_{2} \mathrm{O}_{3}$ suggests it is mainly associated with the clay fraction, although some sandstones plot above the 
sorting trend at $\sim 10-13$ wt $\% \mathrm{Al}_{2} \mathrm{O}_{3}$, suggesting partial control by heavy minerals such as zircon or monazite (Fig. 5c). Strong negative correlation between $\mathrm{Zr}$ and $\mathrm{Al}_{2} \mathrm{O}_{3}$ (Fig. 5d) is a clear indication of a heavy mineral effect, with preferential concentration of zircons in the very fine sand fraction. Linear trends for Sc (Fig. 5e), $\mathrm{Ni}$ (not illustrated) and $\mathrm{Cr}$ (Fig. 5f) with $\mathrm{Al}_{2} \mathrm{O}_{3}$ suggests
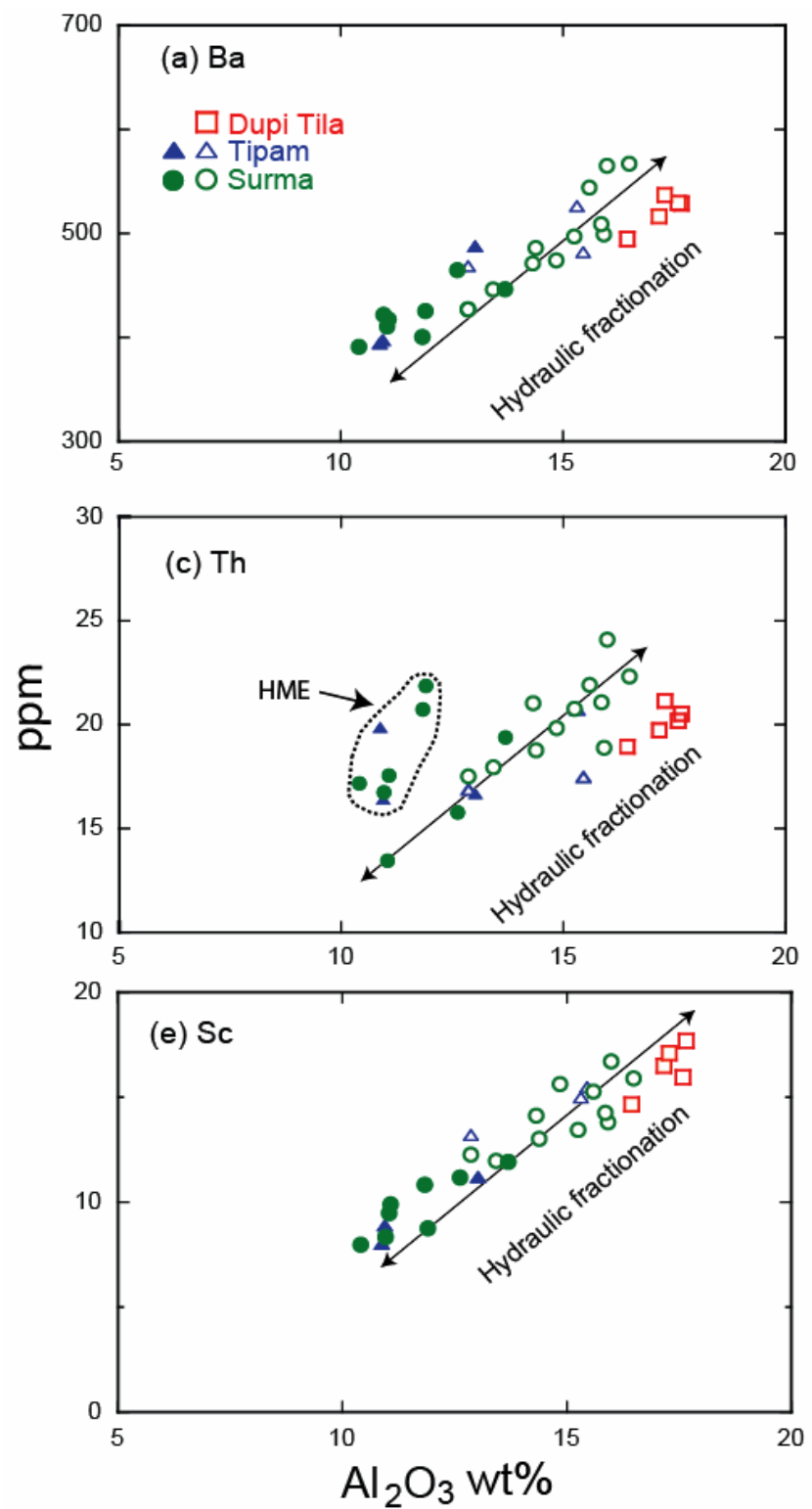

their association with clays produced from the weathering of ferromagnesian minerals, as for $\mathrm{MgO}$ and $\mathrm{Fe}_{2} \mathrm{O}_{3}$. However, slight enrichment of $\mathrm{Cr}$ in some Surma sandstones and mudrocks from the main trend in $\mathrm{Al}_{2} \mathrm{O}_{3}$-Cr space suggests the presence of chromite or Cr-spinels (Fig. 5f).
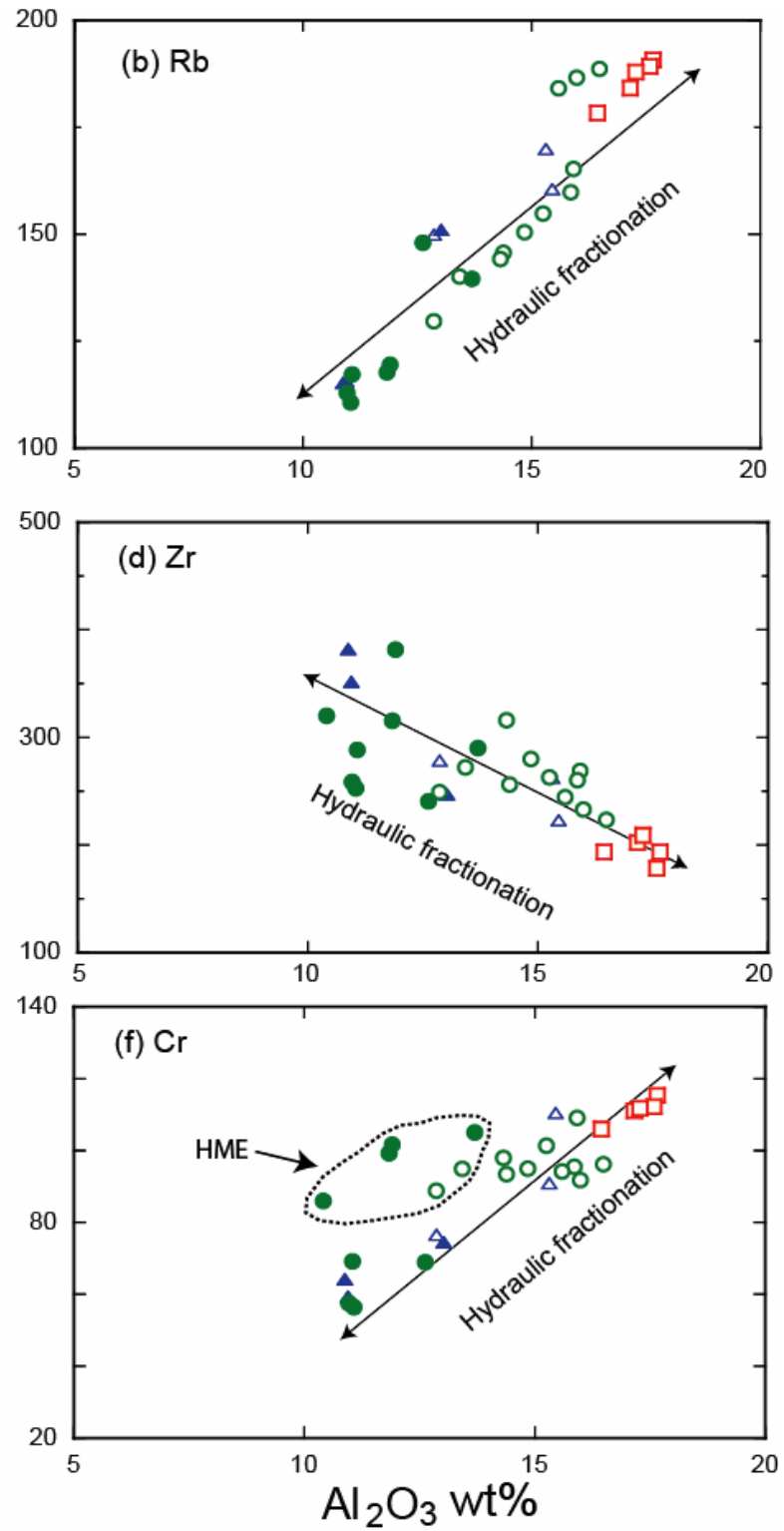

Figure 5 Selected trace element- $\mathrm{Al}_{2} \mathrm{O}_{3}$ variation diagrams for the Shahbajpur-1 drill hole sandstones and mudrocks. HME- heavy mineral effects.

The main features of the bivariate plots are the marked linear trends and the quite clear separation of the sandstones and mudstones. This and the intercepts of many elements with the $\mathrm{x}$-axis at $\sim 5-7 \mathrm{wt} \% \mathrm{Al}_{2} \mathrm{O}_{3}$ reflects sorting, with hydrodynamic separation of coarser quartz and a subordinate quantity of feldspar from fine-grained illitic and smectitic clays. Some heavy mineral effects are evident, however, as shown by the negative trend for $\mathrm{Zr}$, and sporadic enrichments of $\mathrm{Th}$ and $\mathrm{Cr}$ in some samples. 


\section{Upper Continental Crust (UCC) normalization}

Lithotype averages for each group were normalized against UCC (Fig. 6) to examine relative enrichment or depletion relative to the crustal values of Rudnick and Gao (2005). All three groups display similar patterns, with marked depletion in the mobile elements $\mathrm{CaO}$, $\mathrm{Na}_{2} \mathrm{O}$ and $\mathrm{Sr}$, and moderate depletion in $\mathrm{K}_{2} \mathrm{O}$ relative to UCC. Dupi Tila mudrocks show the greatest depletion in $\mathrm{CaO}$. Among the remaining elements $\mathrm{Zr}$, Th, Sc, $\mathrm{Y}$, $\mathrm{TiO}_{2}, \mathrm{Ni}, \mathrm{Cr}$ and $\mathrm{V}$ are slightly enriched, especially for the mudrocks. However, in the segment of mainly ferromagnesian elements from Sc to V, the Dupi Tila mudrocks are slightly more enriched than Surma and Tipam equivalents (Fig. 6). Furthermore, the Surma and Tipam mudrocks are enriched in trace elements relative to the sandstones, which are slightly depleted relative to UCC. These compositional variations between lithotypes reflect sorting, but those between groups indicate some contrasts in provenance and modifying factors such as weathering. These aspects will be discussed below.

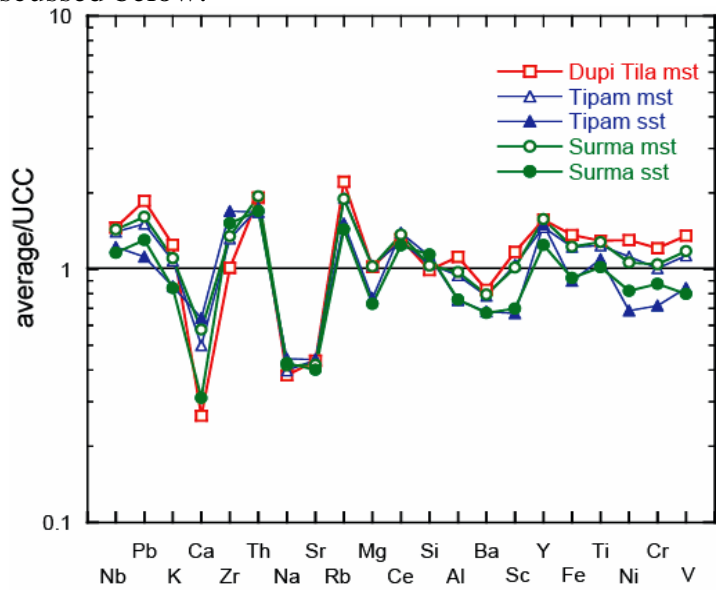

Figure 6 Average major and trace element abundances of Shahbajpur-1 sandstones and mudrocks normalized to the composition of the UCC (Rudnick and Gao 2005). Elements are arranged from left to right in order of increasing abundances in average Mesozoic-Cenozoic sandstone(Condie1993) relative to UCC, following the methodology of Dinelli et al. (1999). Majors are normalized as $\mathrm{wt} \%$.

\section{Discussion}

\section{Sediment genesis}

The nature of source rock composition can be gleaned from major and trace element data of sedimentary rocks, as successfully used in the literature (Roser and Korsch 1988; McLennanet al.1993; Hossain et al. 2010; Yang et al. 2011).

\section{Major element discrimination}

Roser and Korsch (1988) proposed discriminant functions for sedimentary provenance analysis, based on major element compositions. On this diagram, all of the SB-1 samples fall in the quartzose $(P 4)$ provenance field (Fig. 7). The Surma and Tipam sandstones fall in a cluster, slightly separated from the mudrocks. Collectively the data define a trend originating from the join between the felsic (P3) and intermediate (P2) fields, well displaced from the igneous source line. Sediments recycled from felsic sources plot progressively away from the igneous source line into the P4 field, as illustrated by Roser (2000). The distribution of the SB-1 sediments on this plot thus suggests recycling of sediments from a felsic source, with an average composition near rhyodacite (Fig. 7). Furthermore, the SB-1 data fall within the field of coeval Sylhet trough (Province 2) sediments of Himalayan derivation (Hossain et al. 2010). This indicates a similar source for the Hatia sediments.

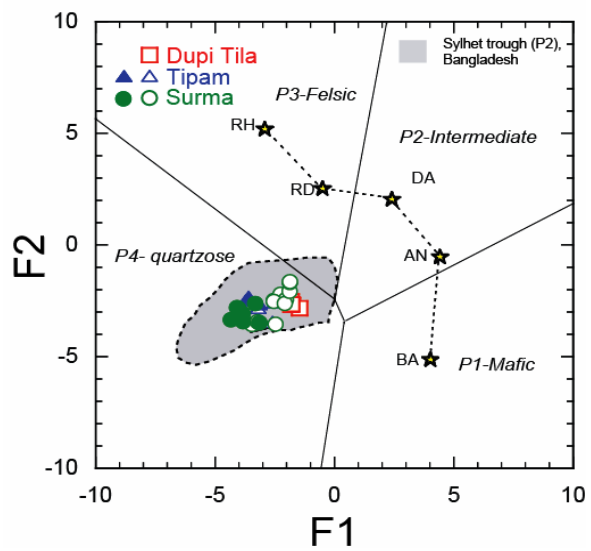

Figure 7 Major element provenance discriminant function diagram (Roser \& Korsch 1988) for Shahbajpur-1 sandstones and mudrocks. Field is for Province 2 Sylhet basin sediments (Surma and Tipam Groups) from data in Hossain et al.(2010)(drill core samples only). Stars: BA, AN, DA, RD, RH-average basalt, andesite, dacite, rhyodacite and rhyolite, as plotted by Roser and Korsch (1988).

Source composition can also be assessed using the A$\mathrm{CN}-\mathrm{K}$ molecular proportion diagram of Nesbitt and Young (1984). On this diagram, sedimentary suites trend from the feldspar join towards the " $\mathrm{A}$ " apex, running parallel to the A-CN join, along an ideal weathering trend (IWT). However, most lithified sediments trend to the right of the IWT, due to gain in potassium from K-metasomatism (Fedo et al. 1995; Hossain et al. 2012). The Surma, Tipam and Dupi Tila sediments form a single trend, and backward projection intersects the igneous source line between dacite and granite (Fig. 8), also indicating that they were derived from a relatively felsic source. The SB-1 data also lie along the trend of the coeval Sylhet trough (P2) succession (Hossain et al. 2010). 


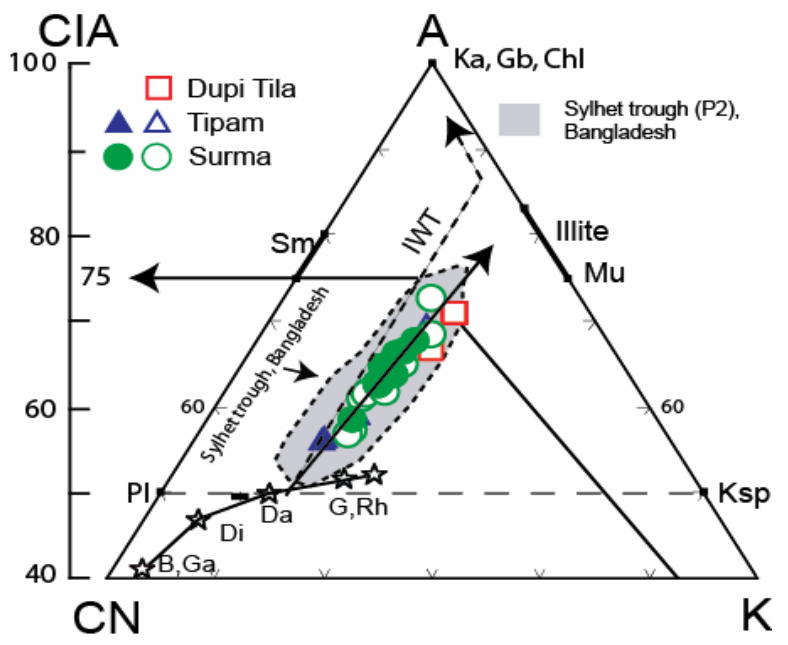

Figure 8 A-CN-K diagram (Nesbitt and Young 1984) for Shahbajpur1 drill hole sandstones sediments. $\mathrm{A}=\mathrm{Al}_{2} \mathrm{O}_{3}, \mathrm{CN}=\mathrm{CaO}+$ $\mathrm{Na}_{2} \mathrm{O}, \mathrm{K}=\mathrm{K}_{2} \mathrm{O}$, CIA = Chemical Index of Alteration, $\mathrm{Ka}=$ kaolinite, $\mathrm{Gb}=$ gibbsite, $\mathrm{Chl}=$ chlorite, $\mathrm{Mu}=$ muscovite, $\mathrm{Pl}$ $=$ plagioclase, $\mathrm{Ksp}=\mathrm{K}$-feldspar, $\mathrm{Sm}=$ smectite. The solid line linking crosses is the compositional trend in pristine average igneous rocks (data of Le Maitre 1976). $\mathrm{B}$ = basalt, $\mathrm{Ga}=$ gabbro, $\mathrm{Di}=$ diorite, $\mathrm{Da}=$ dacite, $\mathrm{G}=$ granite, $\mathrm{Rh}=$ rhyolite. Dashed line parallel to the A-CN edge is the ideal weathering trend (IWT). Sylhet field (Surma and Tipam Group) from data in Hossain et al. (2010).

\section{Trace element discrimination}

Immobile trace elements have been widely used in provenance studies, because of their low solubility and short residence times in natural waters; consequently such elements are transferred quantitatively from the source to the depositional basin (Taylor and McLennan 1985; McLennan et al. 1993; Roser 2000 and many others). Immobile elemental ratios are particularly useful, as they are not modified by quartz dilution or the formation of carbonate cements.

On a $\mathrm{Th} / \mathrm{Sc}-\mathrm{Zr} / \mathrm{Sc}$ ratio-ratio plot (after McLennan et al. 1993) the Surma, Tipam and Dupi Tila Groups sediment lie on a single trend that is slightly oblique to the primary compositional trend (PCT) (Fig. 9). Dupi Tila mudrocks plot at the lower end of the distribution. However, the intersection of the trend with the PCT at high $\mathrm{Th} / \mathrm{Sc}$ and $\mathrm{Zr} / \mathrm{Sc}$, indicating derivation from a felsic source rock intermediate in composition between average rhyolite and dacite. The SB-1 data also lie within the field of coeval Sylhet trough (P2) sediments (Hossain et al. 2010). A second combination of trace elements ( $\mathrm{Ti} / \mathrm{Zr}-\mathrm{Ce} / \mathrm{Sc}$ ) shows exactly the same pattern, and identical ratios to the Sylhet sediments (Fig. 10). The immobile trace elements thus clearly indicate felsic source, as shown by the major elements.

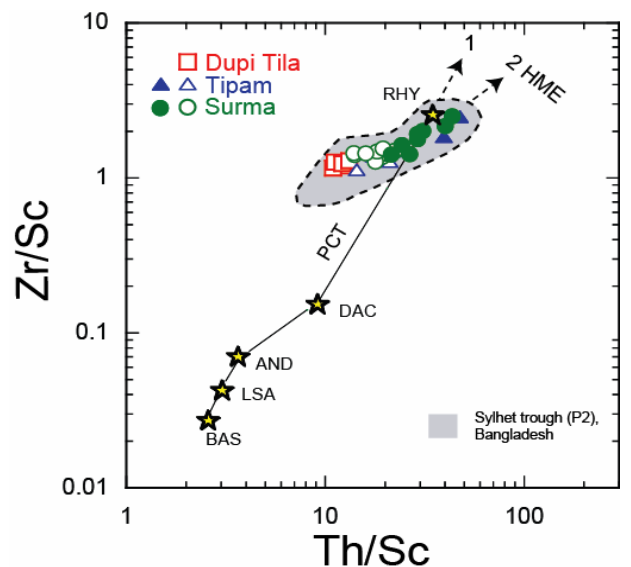

Figure $9 \mathrm{Th} / \mathrm{Sc}-\mathrm{Zr} / \mathrm{Sc}$ diagram (McLennan et al. 1993, Roser and Korsch 1999) for Shahbajpur-1 sediments. Stars marked BAS (basalt), LSA (low silica andesite), DAC (dacite) and RH (rhyolite) are average volcanic rock compositions (Taylor 1965, as plotted by Roser and Korsch 1999). Arrow (Trend 2) indicates heavy mineral effects (HME). PCT - primary compositional trend. Sylhet field (Surma and Tipam Group) from data in Hossain et al. (2010).

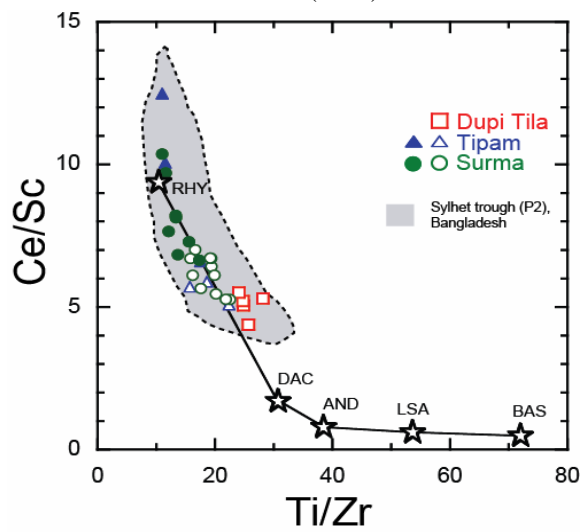

Figure $10 \mathrm{Ce} / \mathrm{Sc}-\mathrm{Ti} / \mathrm{Zr}$ diagram for Shahbajpur-1 drill hole sandstones (filled symbols) and mudrocks (open symbols). Stars marked BAS (basalt), LSA (low silica andesite), DAC (dacite) and RHY (rhyolite) are average volcanic rock compositions (Taylor 1965). Sylhet field (Surma and Tipam Group) from data in Hossain et al. (2010).

\section{Weathering conditions}

Geochemical compositions of sediments may be modified by the weathering conditions in the source area, and hence climate (Nesbitt and Young 1982; Young and Nesbitt 1999; Clift et al. 2008; Absar et al. 2009; Guo et al. 2012).

Nesbitt and Young (1982) proposed the Chemical Index of Alteration (CIA) as a method of quantifying the intensity of weathering in the source areas of sediments. CIA measures the extent to which fresh feldspars in the source rock have been converted to clays. The index is calculated from molecular proportions, using the formula: 


\section{CIA=molar $\left[\left(\mathrm{Al}_{2} \mathrm{O}_{3}\right) /\left(\mathrm{Al}_{2} \mathrm{O}_{3}+\mathrm{CaO} *+\mathrm{Na}_{2} \mathrm{O}+\mathrm{K}_{2} \mathrm{O}\right)\right] \mathrm{x} 100$;}

where $\mathrm{CaO}^{*}$ is the $\mathrm{CaO}$ contained in silicate minerals only. Our data have been corrected for $\mathrm{Ca}$, present in apatite but no correction has been made for carbonate due to lack of $\mathrm{CO}_{2}$ data.

As observed in many sedimentary successions, CIA values of mudrocks are generally greater than those of interbedded sandstones (Roser 2000; Hossain et al. 2010), and the Hatia samples are no exception. The mudrocks therefore give an indication of the maximum weathering in the source. CIA values for the Surma mudrocks range from 57 to 70 (average 63), versus 5969 (av. 63) for Tipam mudrocks, and more uniform values of 69-71 (av. 70) for the Dupi Tila mudrocks. Surma Group sandstones yield values similar to the mudrocks (CIA av. 64). The results show the Surma and Tipam sediments record low to moderate weathering intensity, and values in the Dupi Tila sediments are only slightly greater.

Simple CIA calculations for ancient sediments can give values lower than original CIA due to post-depositional diagenetic effects (K-metasomatism), as described by Fedo et al. (1995). However, these effects can be overcome by projection on a ternary A-CN-K plot, which allows estimation of the pre-metasomatic value (Fedo et al. 1995). On the A-CN-K diagram, the Surma, Tipam and Dupi Tila Groups follow a path originating from the igneous source line between granite to dacite, and trending towards illite on the A-K edge (Fig. 8). The trend deviates from the ideal weathering path and is displaced toward the K-apex, indicating moderate $\mathrm{K}$ metasomatism has occurred. Projection from the K-apex to connect with the IWT, following the methodology of Fedo et al. (1995), yields corrected maximum CIA values of 75 for the Surma and Dupi Tila Group and 73 for Tipam Group sediments.

On the A-CN-K diagram the Hatia sediments spread from a position near the igneous source line, to higher values in the mudrocks (Fig. 8). This distribution indicates non-steady state weathering condition in the source area, where active tectonism permits erosion of sediments from all zones of the weathering profile (Nesbitt et al. 1996). This interpretation is compatible with derivation of the sediments from the active Himalaya uplift, which supplies weathered sediments from the upper zones of weathering profiles and fresh detritus from the lower zones. The trend of the Hatia sediments on the A-CN-K diagram coincides perfectly with that for the Sylhet trough (P2) succession (Hossain et al. 2010), suggesting similar moderate weathering history in the source region of both successions.

\section{Effects of sedimentary processes}

Hydraulic sorting, recycling and heavy mineral concentration during sedimentary processes can significantly modify the geochemical compositions of sediments (Johnsson 1993; Roser 1996a, b; Roser 2000; Corcoran 2005; Tripathi et al. 2007; EtemadSaeed et al. 2011).

\section{Sorting}

Sorting produces geochemical contrasts between sandstones and mudrocks due to separation of sand and mud by hydraulic fractionation. The degree of sorting is controlled by the source to sink distance, energy of the transport system, and many other factors. The effects of sorting can be evaluated on $\mathrm{Al}_{2} \mathrm{O}_{3}$-element plots (Harker variation diagrams) based on the degree of compositional separation between sandstones and mudrocks, and by the extent of fractionation between end-member extremes. Almost all Harker plots for the Hatia sediments show considerable contrast in elemental abundances between sandstones and mudrocks with a relatively clear break at $11-13 \mathrm{wt} \%$ $\mathrm{Al}_{2} \mathrm{O}_{3}$ (e.g. Figs 4 and 5), and linear trends. These features illustrate the effects of sorting in the sediment routing system.

Similar sorting effects are evident in the Sylhet trough (P2) sediments (Hossain et al. 2010). The Sylhet trough is believed to have been part of the same dispersal system, and is located about $500 \mathrm{~km}$ north of the Hatia trough. The SB-1 sediments show tighter, narrower and more uniform distribution patterns than Sylhet trough sediments (Figs 7, 8, 9, 10), possibly due to their longer transport distance from the source area, and more effective sorting.

\section{Heavy mineral concentration}

Heavy mineral concentration may significantly influence the geochemical composition of sediments, but these effects can be assessed using ratio-ratio plots involving elements that are sensitive to such concentrations (McLennan 1989; McLennan et al. 1993). For example, on the Th/Sc- $\mathrm{Zr} / \mathrm{Sc}$ plot the SB-1 sediments display two trends (Fig. 9). The first (trend 1) indicates compositional variation of the source rock, and the second (trend 2) indicates sedimentary heavy mineral concentration due to sorting. All Hatia mudrocks plot to the left of the PCT, whereas Surma and Tipam sandstones plot obliquely across the PCT, due to preferential concentration of resistant zircons in the sand size grades (Fig. 5d). Similar trends are seen in the Sylhet trough (P2) sediments (Hossain et al. 2010). 
$\mathrm{Ce} / \mathrm{Sc}$ and $\mathrm{Ti} / \mathrm{Zr}$ ratios are also fractionated between the SB-1 sandstones and mudrocks (Fig. 10). The relationship between $\mathrm{Al}_{2} \mathrm{O}_{3}$ and $\mathrm{TiO}_{2}$ (Fig. 4e) indicates sporadic enrichment of $\mathrm{TiO}_{2}$ in some sandstones, probably due to the concentration of a Ti-bearing heavy mineral such as titanite, rutile, or anatase. Enrichment of Ce (not illustrated) and Th in Surma and Tipam sandstones (Fig. 5c) and positive correlation between Th and Ce (not illustrated) suggests the hydrodynamic concentration of heavy minerals such as monazite and apatite in some samples. Preferential concentration of mafic heavy minerals (e.g. chromite, Cr-spinel, magnetite, ilmenite) may be responsible for the occasional enrichments of ferromagnesian elements in some samples (e.g. Cr, Fig. 5f).

\section{Depositional basin dynamics}

Major and trace element compositions of sedimentary rocks have been widely used in the literature to elucidate the tectonic setting of the depositional basins, based on discrimination plots (Maynard et al. 1982; Roser and Korsch 1986; Bhatia and Crook 1986), although such discrimination should be used with caution (Armstrong-Altrin et al. 2005; Ryan and Williams 2007).

\section{Major elements}

The ratios $\mathrm{SiO}_{2} / \mathrm{Al}_{2} \mathrm{O}_{3}$ and $\mathrm{K}_{2} \mathrm{O} / \mathrm{Na}_{2} \mathrm{O}$ (Maynard et al. 1982) have been used to broadly identify the tectonic setting of depositional basins, and have been combined (Fig. 11) in the discrimination plot of Roser and Korsch (1986). This discriminant seeks to separate immature and evolved arc (A1 and A2, respectively), active continental margin (ACM), and passive margin settings. Passive margin sediments are normally derived from stable cratons, and are deposited in passive (nonsubductive) continental margin settings or in intracratonic basins. On this discrimination plot, the Surma and Tipam sandstones plot well within the passive margin field, whereas their mudrock equivalents trend downward to the edge of the ACM field. Dupi Tila mudrocks fall on the tie line, and within ACM. However, an ACM depositional setting is inconsistent with the paleogeography of the Dupi Tila sediments. In this case the apparent ACM classification is simply of a reflection of sorting fractionation. Overall the distribution of the sediments indicates that the SB-1 sequence was deposited in a passive margin (PM) setting, albeit in a rapidly subsiding basin.

\section{Trace elements}

Immobile trace elements have also been used to identify tectonic setting of depositional basins, as in the discriminant of Bhatia and Crook (1986). They proposed methods of distinguishing oceanic island arc (OIA), continental island arc (CIA), active continental margin (ACM) and passive margin (PM). On their ThSc-Zr/10 plot (Fig. 12) almost all the Surma and Tipam sandstones fall within the PM field, and the remainder

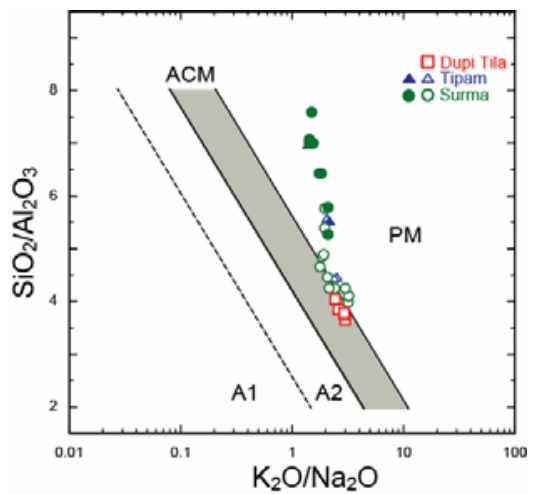

Figure $11 \mathrm{SiO}_{2} / \mathrm{Al}_{2} \mathrm{O}_{3}-\mathrm{K}_{2} \mathrm{O} / \mathrm{Na}_{2} \mathrm{O}$ diagram (after Maynard et al. 1982; Roser \& Korsch 1986) for Shahbajpur-1 drill hole sediments. A1 - arc setting, basaltic and andesitic detritus; A2 - evolved arc setting, felsitic-plutonic detritus; ACM active continental margin; $\mathrm{PM}$ - passive margin.

are transitional between ACM and PM. The mudrocks fall within ACM and the ACM-PM transition zone. However, this plot was developed using sandstone data, and mudrocks will not necessarily give reliable classifications. The Hatia sediments overall display a trend from near UCC and ACM into PM. This suggests that the Surma, Tipam and Dupi Tila sediments were derived from the upper crustal section of the Himalaya within the Eurasian plate, and were deposited in the subsiding Hatia basin in a passive margin setting. The trend toward the $\mathrm{Zr}$ apex reflects sorting, but also zircon concentration during recycling (McLennan et al. 1993). This is the basis for PM classification on this plot. The results from the trace elements are consistent with those from the major elements.

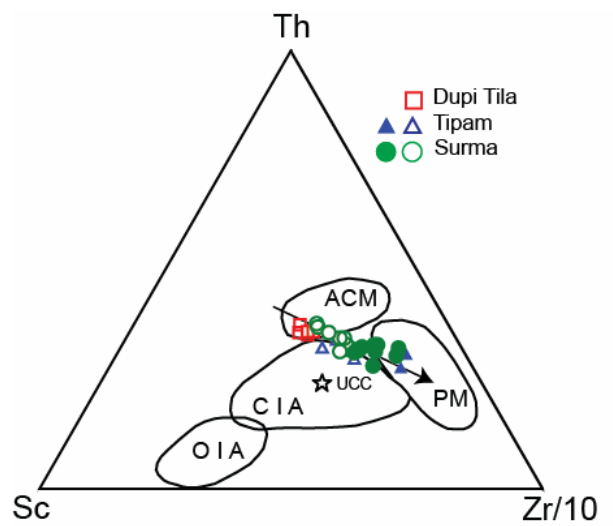

Figure 12 Th-Sc-Zr/10 (Bhatia and Crook 1986) for Shahbajpur-1 sediments. PM-passive margin; ACM-active continental margin; CIA-continental island arc; OIA-oceanic island arc. UCC-upper continental crust (data of Rudnick and Gao 2005). 


\section{Paleogeographic speculations}

The three geological provinces (P1, P2 and P3) of the Bengal Basin should be considered separately to get better understanding on the geological processes (Reimann 1993; Najman 2006). The geochemical signatures in the SB-1 Tertiary sequence described here are virtually identical to those of the coeval P2 succession in the Sylhet trough. Elemental abundances and estimates of source rock composition and weathering history in SB-1 match those seen in P2. Moreover, on all comparison diagrams the SB-1 sediments are more homogeneous in composition and form more compact and narrower distributions than the coeval P2 sediments (Figs 7, 8, 9 and 10). This suggests that the same dispersal system fed both the Sylhet P2 and Hatia SB-1 successions. The greater homogeneity seen in the Hatia data may reflect more distal deposition, and hence longer transport distance from the same source.The comparisons overall support the proposals by Alam et al. (2003) and Najman et al. (2008) that the Hatia trough represents an extension of the P2 Sylhet trough, and that the successions are essentially correlative.

\section{Conclusions}

The whole-rock geochemistry of the Hatia succession in SB-1 records the control of modifying factors including source rock composition, weathering in the source region, sorting, heavy mineral concentration, recycling, diagenesis, and tectonic setting of the depositional basin. The combination of these factors produced the elemental variation in the sediments. The entire SB-1 sequence was derived from a uniform felsic source, consistent from derivation from the Himalayan uplift. Surma, Tipam and Dupi Tila sediments all record moderate non steady-state weathering and hence active uplift in the source region, and moderate postdepositional K-metasomatism. Sorting and hydraulic separation of quartz and feldspar from clays produced marked linear geochemical trends and sporadic heavy mineral concentration. Both major and trace element compositions are compatible with deposition in a basin at a passive margin setting. Geochemically, the SB-1 succession is virtually identical to coeval P2 sediments in the Sylhet trough succession. These features support the hypothesis of Alam et al. (2003) and Najman (2006) that the Hatia trough is an extension of Province 2. More homogenous composition in the Hatia sequence may reflect increased transport distance from the same source that fed the Sylhet trough.

Acknowledgements: We are grateful to PETROBANGLA (Bangladesh Oil, Gas and Mineral Corporation) and BAPEX (Bangladesh Petroleum Exploration and
Production Company) for providing drill core. Muhammad Imadduddin is thanked for his kind permission to access drill cores. Special thanks are also due to Professor Syed Samsuddin Ahmed, Md. Sultan-Ul-Islam, Mrinal Kanti Roy, Ismail Hossain and Narantuya Purevjav for their encouragement and suggestions. This work was supported by a Monbukagakusho (MEXT) scholarship (to DKR) and internal research funding (to BPR), during the M.Sc and Ph.D. studies of the first author. We also acknowledge two anonymous reviewers for their constructive comments.

\section{References}

Absar N, Mahshar R, Roya M, Naqvi SM and Roya AK. 2009. Composition and weathering conditions of Paleoproterozoic upper crust of Bundelkhand craton, Central India: Records from geochemistry of clastic sediments of 1.9 Ga Gwalior Group. Precamb. Res. 168: 313-329.

Alam M, Alam MM, Curray JR, Chowdhury, MLR and Gani MR 2003. An overview of the sedimentary geology of the Bengal basin in relation to the regional framework and basin-fill history. Sed. Geol. 155: 179-208.

Armstrong-Altrin JS, Lee YI, Verma SP and Ramasamy S. 2004. Geochemistry of sandstones from the Upper Miocene Kudankulam Formation, Southern India: Implications for provenance, weathering, and tectonic setting. Jour. Sed. Res. 74: 285-297.

BAPEX 1995. Petroleum geology of Bangladesh. Core Lab. Rep. 139 pp.

Bhatia MR and Crook KAW 1986. Trace element characteristics of graywackes and tectonic setting discrimination of sedimentary basins. Contrib. Mineral. Petrol. 92: 181-193.

Campos-Alvarez NO and Roser BP. 2007. Geochemistry of black shales from the Lower Cretaceous Paja Formation, Eastern Cordillera, Colombia: source weathering, provenance, and tectonic setting. Jour. South Amer. Earth. Sci. 23: 271-289.

Clift PD, Hodges KV, Heslop D, Hannigan R, Long HV and Claves G. 2008. Correlation of Himalayan exhumation rates and Asian monsoon intensity. Nature Geosci. 1: 875-880.

Condie KC. 1993. Chemical composition and evolution of the upper continental crust: contrasting results from surface samples and shales. Chem. Geol. 104, 1-37.

Corcoran PL. 2005. Recycling and chemical weathering in tectonically controlled Mesozoic-Cenozoic basins of New Zealand. Sedimentology 52: 757-774.

Dinis PA, Oliveira A, Rocha F, Vieira M and Cunha PP. 2011. Evolution in the provenance of a tectonically controlled PlioPleistocene alluvial system between the Variscan Iberian Massif and the Atlantic margin, Portugal. Chem. de Erde 71: 267-278.

Dinelli E, Lucchini F, Mordenti A and Paganelli L. 1999. Geochemistry of Oligocene-Miocene sandstones of the northern Apennines (Italy) and evolution of chemical features in relation to provenance changes. Sed. Geol. 127, 193-207.

Etemad-Saeed N, Hosseini-Barzi M and Armstrong-Altrin JS. 2011. Petrography and geochemistry of clastic sedimentary rocks as evidences for provenance of the Lower Cambrian Lalun Formation, Posht-e-badam block, Central Iran. J. African Earth Sci. 61, 142-159.

Fedo CM, Nesbitt HW and Young GM. 1995. Unraveling the effects of potassium metasomatism in sedimentary rocks and paleosols, with implications for paleoweathering conditions and provenance. Geology 23: 921-924.

Guo Q, Xiao W, Windley BF, Mao Q, Han C, Qu J, Ao S, Li J, Song D and Yong Y. 2012. Provenance and tectonic settings of Permian turbidites from the Beishan Mountains, NW China: Implications for the Late Paleozoic accretionary tectonics of the southern Altaids. $J$. Asian Earth Sci. 49, 54-68. 
Herron MM. 1988. Geochemical classification of terrigenous sands and shales from core or log data. J. Sed. Pet. 58 (5): 820-829.

Hossain HMZ, Roser BP and Kimura J-I. 2010. Petrography and whole-rock geochemistry of the Tertiary Sylhet succession, northeastern Bengal Basin, Bangladesh: Provenance and source area weathering. Sed. Geol. 228: 171-183.

Johnsson MJ. 1993. The system controlling the composition of clastic sediments. In Johnsson MJ and Basu A. (Eds.), Processes Controlling the Composition of Clastic Sediments. Geol. Soc. Amer. Spec. Pap. 284: 1-19.

Kimura JI and Yamada Y 1996. Evaluation of major and trace element XRF analyses using a flux to sample ratio of two to one glass beads. J. Mineral. Petrol. Econ. Geol. 91: 62-72.

Le Maitre RW 1976. The chemical variability of some common igneous rocks. J. Pet. 17, 589-637.

Long X, Yuan C, Sun M, Xiao W, Wang Y, Cai K and Jiang Y. 2011. Geochemistry and Nd isotopic composition of the Early Paleozoic flysch sequence in the Chinese Altai, Central Asia: Evidence for a northward-derived mafic source and insight into model ages in accretionary orogen. Gond. Res. (in press).

Maynard JB, Valloni R and Yu HS. 1982. Composition of modern deepsea sands from arc-related basins: in Leggett, J.K., eds., Trench forearc geology: sedimentation and tectonics on modern and ancient active plate margins. Geol. Soc. Lond. Spec. Pub. 10: 551-561.

McLennan SM. 1989. Rare earth elements in sedimentary rocks: influence of provenance and sedimentary processes. Rev. Min. 21, 169-200.

McLennan SM, Hemming S, McDaniel DK and Hanson GN. 1993. Geochemical approaches to sedimentation, provenance and tectonics: in Johnsson, M.J., and Basu, A., eds., Processes Controlling the Composition of Clastic sediment. Geol. Soc. Amer. Spec. Pap. 284: 1-19.

Mondal D, Islam MS and Islam MA. 2009. Electrofacies analysis of Neogene sequence in the well Shahbajpur \# 1, Bhola, Bengal Basin. ICFAI. J. Earth Sci. 3 (1), 57-74.

Najman Y. 2006. The detrital record of orogenesis: A review of approaches and techniques used in the Himalayan sedimentary basins. Earth Sci. Rev. 74, 1-72.

Najman Y, Bickle M, Boudagher-Fadel M, Carter A, Garzanti E, Paul M, Wijbrans J, Willett E, Oliver G, Parrish R, Akhter H, Allen R, Ando S, Chisty E, Reisberg L and Vezzoli G. 2008. The Paleogene record of Himalayan erosion: Bengal Basin, Bangladesh. Earth Plan. Sci. Lett. 273: 1-14.

Nesbitt HW and Young GM. 1984. Prediction of some weathering trends of plutonic and volcanic rocks based on thermodynamic and kinetic considerations. Geochim. Cosmochim. Acta. 48: 1523-1534.

Nesbitt HW and Young GM. 1982. Early Proterozoic climates and plate motions inferred from major element chemistry of lutites. Nature 299: 715-717.

Nesbitt HW, Young GM, McLennan SM and Keays RR. 1996. Effects of chemical weathering and sorting on the petrogenesis of siliciclastic sediments, with implications for provenance studies. J. Geol. 104: 525-542.

Pettijohn FJ, Potter PE and Siever R. 1972. Sand and sandstone. Springer-Verlag, New York. 618 pp.

Raymo ME and Ruddiman WF. 1992. Tectonic forcing of the Late Cenozoic climate. Nat. 359: 117-122.

Rahman MJJ and Faupl P. 2003. The composition of the subsurface Neogene shales of the Surma group from the Sylhet Trough, Bengal Basin, Bangladesh. Sed. Geol. 155: 47-417.

Rahman MJJ and Suzuki S. 2007a. Geochemistry of sandstones from the Miocene Surma Group, Bengal Basin, Bangladesh: Implication for provenance, tectonic setting and weathering. Geochem. J. 41: 415-428.
Rahman MJJ and Suzuki S. 2007b. Composition of Neogene shales from the Surma Group, Bengal Basin, Bangladesh: Implication for provenance and tectonic setting. Austrian J. Earth Sci. 100: 54-64.

Rahman MJJ, McCann T, Abdullah R and Yeasmin R. 2011. Sandstone diagenesis of the Neogene Surma Group from the Shahbajpur gas field, southern Bengal Basin, Bangladesh. Austrian J. Earth Sci. 104, 114-126.

Reimann KU. 1993. Geology of Bangladesh. Gebruder Borntraeger, Berlin. 160 pp.

Roser BP. 1996a. Sandstone geochemistry, provenance, and tectonic setting: 2. Effects of grain size on the $\mathrm{Al}_{2} \mathrm{O}_{3} / \mathrm{SiO}_{2}$-basicity index diagram, and application to recycled and medium-grade metamorphic terranes of New Zealand. Earth Sci. (Chikyu Kagaku) 50: 238-250.

Roser BP. 1996b. Sandstone geochemistry, provenance and tectonic setting: 1.-Application of the $\mathrm{Al}_{2} \mathrm{O}_{3} / \mathrm{SiO}_{2}$-Basicity Index diagram to New Zealand sedimentary suites. Earth Sci. (Chikyu Kagaku), 50: 138-147.

Roser BP. 2000. Whole-rock geochemical studies of clastic sedimentary suites. Mem. Geol. Soc. Japan 57: 73-89.

Roser BP and Korsch RJ. 1986. Determination of tectonic setting of sandstone mudstone suites using $\mathrm{SiO}_{2}$ and $\mathrm{K}_{2} \mathrm{O} / \mathrm{Na}_{2} \mathrm{O}$ ratio. $J$. Geol. 94: 635-650.

Roser BP and Korsch RJ. 1988. Provenance signatures of sandstonemudstone suites determined using discrimination function analysis of major-element data. Chem. Geol. 67: 119-139.

Roser BP and Korsch RJ. 1999. Geochemical characterization, evolution and source of a Mesozoic accretionary wedge: the Torlesse terrane, New Zealand. Geol. Mag. 136: 493-512.

Roser BP, Sawada Y and Kabeto K. 1998. Crushing performance and contamination trials of a tungsten carbide ring mill compared to agate grinding. Geosci. Rep. Shimane Univ. 17: 1-11.

Ryan KM and Williams DM. 2007. Testing the reliability of discrimination diagrams for determining the tectonic depositional environment of ancient sedimentary basins. Chem. Geol. 5: 54-56.

Rudnick RL and Gao S. 2005. The crust. In Holland HD and Turekian KK. (Eds.), Treatise on Geochemistry. Elsevier Amsterdam. 1-64 pp.

Taylor SR. 1965. The application of trace element data to problems in petrology. In: Ahrens, Physics and chemistry of the Earth (eds. LH Press, F Runcorn, SK and Urey HC), 6, 133-213. Pergamon, Oxford.

Taylor SR and McLennan SM. 1985. The Continental Crust: its Composition and its Evolution. Blackwell, Oxford. 312 pp.

Tripathi JK, Ghazanfari P, Rajamani V and Tandon SK. 2007. Geochemistry of sediments of the Ganga alluvial plains: Evidence of large-scale sediment recycling in the foreland basin of the Himalaya. Quat. Intern. 159: 119-130.

Uddin A and Lundberg N. 1999. A paleo-Brahmaputra? Subsurface lithofacies analysis of Miocene deltaic sediments in the HimalayanBengal system, Bangladesh. Sed. Geol. 123, 239-254.

Yang S, Yim WWS and Huang G. 2008. Geochemical composition of inner shelf Quaternary sediments in the northern South China Sea with implications for provenance discrimination and paleoenvironmental reconstruction. Global Planet. Change. 60, 207-221.

Yang XF, He DF, Wang QC, Tang Y, Tao HF and Li D. 2011. Provenance and tectonic setting of the Carboniferous sedimentary rocks of the East Jungar Basin, China: Evidence from geochemistry and U-Pb zircon geochronology. Gond. Res. (in press).

Young GM and Nebitt HW. 1999. Paleoclimatology and provenance of the glaciogenic Gowganda Formation (Paleoproterozoic), Ontario, Canada: A chemostratigraphic approach. Geol. Soc. Am. Bull. 111, 264-274.

Manuscript received on 7 May 2012 and revised on 7 December 2012 